\title{
Effect of Reaction Temperature on Carbon Yield and Morphology of CNTs on Copper Loaded Nickel Nanoparticles
}

\author{
Hu Ming, ${ }^{1,2}$ Ding Peiling, ${ }^{1}$ Zhang Yunlong, ${ }^{1,2}$ Gao Jing, ${ }^{1,2}$ and Ren Xiaoxue ${ }^{1,2}$ \\ ${ }^{1}$ College of Materials Science \& Engineering, Jiamusi University, Jiamusi 154007, China \\ ${ }^{2}$ Institute of Applied Materials and Technology, Jiamusi University, Jiamusi 154007, China \\ Correspondence should be addressed to Zhang Yunlong; ylzhdr@126.com
}

Received 23 January 2016; Revised 25 February 2016; Accepted 16 March 2016

Academic Editor: Claude Estournès

Copyright (c) $2016 \mathrm{Hu}$ Ming et al. This is an open access article distributed under the Creative Commons Attribution License, which permits unrestricted use, distribution, and reproduction in any medium, provided the original work is properly cited.

\begin{abstract}
This investigation was attempted to introduce carbon nanotubes (CNTs) onto surface of copper powders in order to improve heat transfer performance of copper matrix for engineering application of electrical packaging materials. The $\mathrm{Ni} / \mathrm{MgO}$ catalyst was formed on the copper powders surface by means of codeposition method. CVD technique was executed to fabricate uniform CNTs on copper powders and effect of reaction temperature on the morphology of CNTs was surveyed. The results showed that CNTs products on the copper powder surface were distributed uniformly even if reaction temperature was different. The diameter dimension of CNTs was within the scope of 30 60 nm. Growth behaviors of CNTs by CVD method were considered to be "tipgrowth" mechanism. Raman spectra of CNTs proved that intensity ratio of D-band to G-band $\left(I_{\mathrm{D}} / I_{\mathrm{G}}\right)$ increased as deposition reaction temperature increased, which implied that order degree of graphitic structure in synthesized CNTs improved.
\end{abstract}

\section{Introduction}

Recently, carbon nanotubes (CNTs) had been extensively investigated and attracted attention from researchers due to their extraordinary mechanical and unique electronic properties. Generally, synthesis methods of CNT had been developed to satisfy the engineering application; the main methods were as follows: arc discharge, laser ablation, highpressure carbon monoxide conversion, chemical vapor deposition (CVD), and so forth $[1,2]$. Among the above-mentioned methods, the chemical vapor deposition (CVD) had been successfully applied for the synthesis of carbon nanomaterials. Chemical vapor deposition was considered as a promising preparation technique for production of high quality nanotubes at large scales; effect factors for CVD were composed of carbon source, reaction temperature, catalyst materials, and various flow conditions. In view of weaker interface compatibility, $\mathrm{Fe}\left(\mathrm{NO}_{3}\right)_{3} \cdot \mathrm{H}_{2} \mathrm{O}$ was chosen as the catalyst precursor to synthesize carbon nanotubes (CNTs) on copper fiber substrates by means of one-step chemical vapor deposition method by Xie and coworkers [3]. Iron catalyst was feasible and effective to fabricate carbon nanotubes on copper fiber. The results showed that carbon nanotubes synthesized on the copper fiber would prove the interface binding force between the copper fiber and matrix materials. Katar et al. [4] focused on the synthesis of bamboo-like carbon nanotubes growing directly on copper substrates by sulfur-assisted hot filament chemical vapor deposition with a mixture of $\mathrm{CH}_{4}, \mathrm{H}_{2}$, and $\mathrm{H}_{2} \mathrm{~S}$. SWCNT on copper was fabricated by pyrolysis of ethanol and acetylene and typical temperature of the process was $850^{\circ} \mathrm{C} \sim 950^{\circ} \mathrm{C}$ by Homma et al. [5]. The above-mentioned reports showed that it was possible to synthesize carbon nanotubes on copper matrix (and/or with the participation of $\mathrm{Cu}$ nanomaterials). However, the reaction temperature was high for fabrication of the SWCNT on copper powders or copper foils in the above-mentioned papers. So nickel alloy material was taken into account as the catalyst for their low reaction temperature.

For the engineer application for the electrical contact materials, high performance electrical materials usually need to meet the following requirements [6]: excellent electric conductivity, high withstand voltage characteristics, antiarc erosion, low interception, anticorrosion, a certain strength, and so on. The electrical contact materials were mainly composed 
of matrix phase and reinforcement phase. The copper matrix was widely applied as matrix phase for electrical contact materials due to its electrical and thermal properties. CNTs were extensively investigated as reinforcement phase thanks to their superior mechanical properties and heat transfer performance [7]. So more investigations were focused on the CNTs/Cu composites, in which CNTs were introduced into copper matrix [8-12]. So it had potential importance in application of nanotubes and copper in electronic packaging material field.

However, the density difference between carbon nanotube and copper matrix would result in heterogeneous distribution of the above-mentioned two-phase materials. In order to realize uniform distribution of the carbon nanotube in the copper matrix during the sintering process, we attempted to introduce CNTs onto the surface of copper micrometer particles. The hot-pressed sintering behaviors of $\mathrm{CNTs} / \mathrm{Cu}$ composites will be undergone through in the subsequent research. In the present paper, nickel nanoparticles were formed on the surface of copper powders by means of the codeposition method. We put focus on the fabrication for uniform growth of CNTs on the copper powders by thermal CVD technique. Another target was aimed at inspecting the effect of role of deposition reaction temperature on surface morphology and growth behaviors of CNTs.

\section{Fabrication and Characterization}

Commercial copper powder $(\mathrm{PHI}=75 \mu \mathrm{m})$ was utilized as received material. The solution of nickel nitrate $\left[\mathrm{Ni}\left(\mathrm{NO}_{3}\right)_{2}\right]$ and magnesium nitrate $\left[\mathrm{Mg}\left(\mathrm{NO}_{3}\right)_{2}\right]$ was utilized to form the precursor. Mole ratio for $\mathrm{Ni}\left(\mathrm{NO}_{3}\right)_{2}$ to $\mathrm{Mg}\left(\mathrm{NO}_{3}\right)_{2}$ was $1: 1$. The copper powders were introduced into the $\mathrm{Ni}\left(\mathrm{NO}_{3}\right)_{2} / \mathrm{Mg}\left(\mathrm{NO}_{3}\right)_{2}$ solution by mechanical stirring. Then $\mathrm{Ni}(\mathrm{OH})_{2} / \mathrm{Mg}(\mathrm{OH})_{2} / \mathrm{Cu}$ colloid can be obtained by chemical coprecipitation method. Then compound colloid was thermally treated for $12 \mathrm{~h}$ at $80^{\circ} \mathrm{C}$ under the vacuum condition, which was then crushed into fine powder using mortar. The above-mentioned $\mathrm{Ni}(\mathrm{OH})_{2} / \mathrm{Mg}(\mathrm{OH})_{2} / \mathrm{Cu}$ colloid was carried out in reduction process at $600^{\circ} \mathrm{C}$ for $30 \mathrm{~min}$, heating rate was controlled at $10^{\circ} \mathrm{C} / \mathrm{min}$, and hydrogen was chosen as the reducibility gas. After reduction heat treatment, copper powders coating $\mathrm{Ni} / \mathrm{MgO}$ complex layer (which is abbreviated as $\mathrm{Cu}_{(\mathrm{Ni} / \mathrm{MgO})}$ ) can be obtained; the ratio of $\mathrm{Ni}$ to $\mathrm{MgO}$ was about $80: 20$. After calculation, the ratio of $\mathrm{Ni} / \mathrm{MgO}$ to $\mathrm{Cu}_{(\mathrm{Ni} / \mathrm{MgO})}$ was about $8 \mathrm{wt} . \%$. Then CVD process was carried out at atmospheric pressure in a horizontal alumina tube reactor and the alumina tube was connected to $\mathrm{N}_{2}$ and $\mathrm{CH}_{4}$ gas cylinders. About $500 \mathrm{mg}$ of $\mathrm{Cu}_{(\mathrm{Ni} / \mathrm{Mg})}$ powders in alumina boat was placed at the middle of alumina tube as a reactor zone. The $\mathrm{N}_{2}$ gas was introduced into the reacting furnace under $\mathrm{N}_{2}$ flow rate of $400 \mathrm{sccm}$ and heating rate was controlled at $5^{\circ} \mathrm{C} / \mathrm{min}$ until the reaction temperature is reached. Then methane was introduced to produce CNTs and $\mathrm{N}_{2}$ flow continued when it reached reaction temperature. The gas flow ratio of the $\mathrm{N}_{2}$ to $\mathrm{CH}_{4}$ was $1: 1$ during the reaction process. The reaction time was set as $60 \mathrm{~min}$. As reaction was completed, methane flow was discontinued and $\mathrm{N}_{2}$ flow was continuously filled into a reaction chamber till room

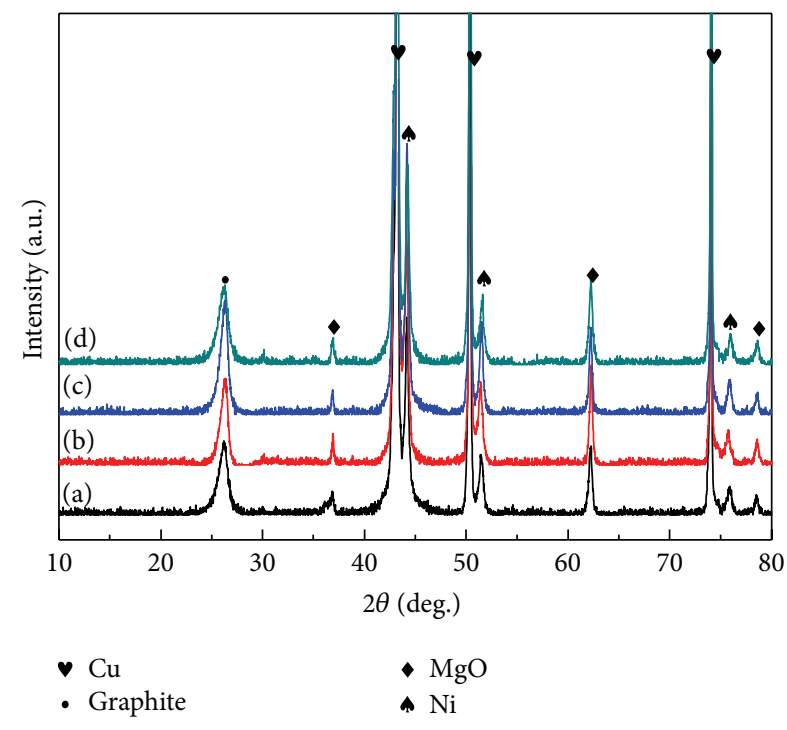

FIGURE 1: XRD pattern of synthetic CNTs under different CVD reaction temperatures. (a), (b), (c), and (d) were reaction products of $\mathrm{Cu}_{(\mathrm{CNTs})}$ at $720^{\circ} \mathrm{C}, 770^{\circ} \mathrm{C}, 820^{\circ} \mathrm{C}$, and $870^{\circ} \mathrm{C}$, respectively.

temperature is reached. The reaction temperature for the $\mathrm{Cu}_{(\mathrm{CNTs})}$ growth was set at $720^{\circ} \mathrm{C}, 770^{\circ} \mathrm{C}, 820^{\circ} \mathrm{C}$, and $870^{\circ} \mathrm{C}$, respectively. The collected black product was subjected to purification. The yield of carbon product after reaction was calculated according to the formula below [9]:

$$
\text { Carbon yield }=\frac{\left(m_{\text {tot }}-m_{\text {cat }}\right)}{m_{\text {cat }}} \times 100 \% \text {, }
$$

where $m_{\text {cat }}$ and $m_{\text {tot }}$ were the mass of the catalyst before and after the reaction, respectively. The phase composition of $\mathrm{Cu}_{(\mathrm{CNTs})}$ was identified by X-ray diffraction (D8 Advance, Germany), the acceleration voltage was $40 \mathrm{kV}$, and scan velocity current was $40 \mathrm{~mA}$. The scanning speed was $4^{\circ} / \mathrm{min}$. Scanning Electron Microscope (JEOL, JSM-6300, Japan) was performed to investigate the morphology of the sample after purification, whose accelerating voltage was set as $20 \mathrm{kV}$. The Photoshop-15 was applied to measure the diameter of the CNTs on the surface of copper powders from the high magnification SEM photos (200000x); at least 20 positions were measured to calculate the average diameter of the CNTs. Defects and graphitic nature were surveyed by Raman spectroscopy (Bruker RFS-27, Germany) equipped with liquid nitrogen cooled setup and with an output power of $10 \mathrm{~mW}$ by means of Nd:YAG laser at a $1064 \mathrm{~nm}$ wavelength. The power on the sample was kept in $10 \mathrm{~mW}$ to avoid damage.

\section{Result and Discussion}

XRD patterns for the reaction products of $\mathrm{Cu}_{(\mathrm{CNTs})}$ at different deposition reaction temperature were illustrated in Figure 1. (a), (b), (c), and (d) were XRD patterns for $\mathrm{Cu}_{(\mathrm{CNTs})}$ at $720^{\circ} \mathrm{C}, 770^{\circ} \mathrm{C}, 820^{\circ} \mathrm{C}$, and $870^{\circ} \mathrm{C}$, respectively. According to $\mathrm{XRD}$ analysis from Figure 1, copper phase was main crystalline phase while $\mathrm{Ni}, \mathrm{MgO}$, and graphite were detected as minor crystalline phase. The right shifts of diffraction peak 

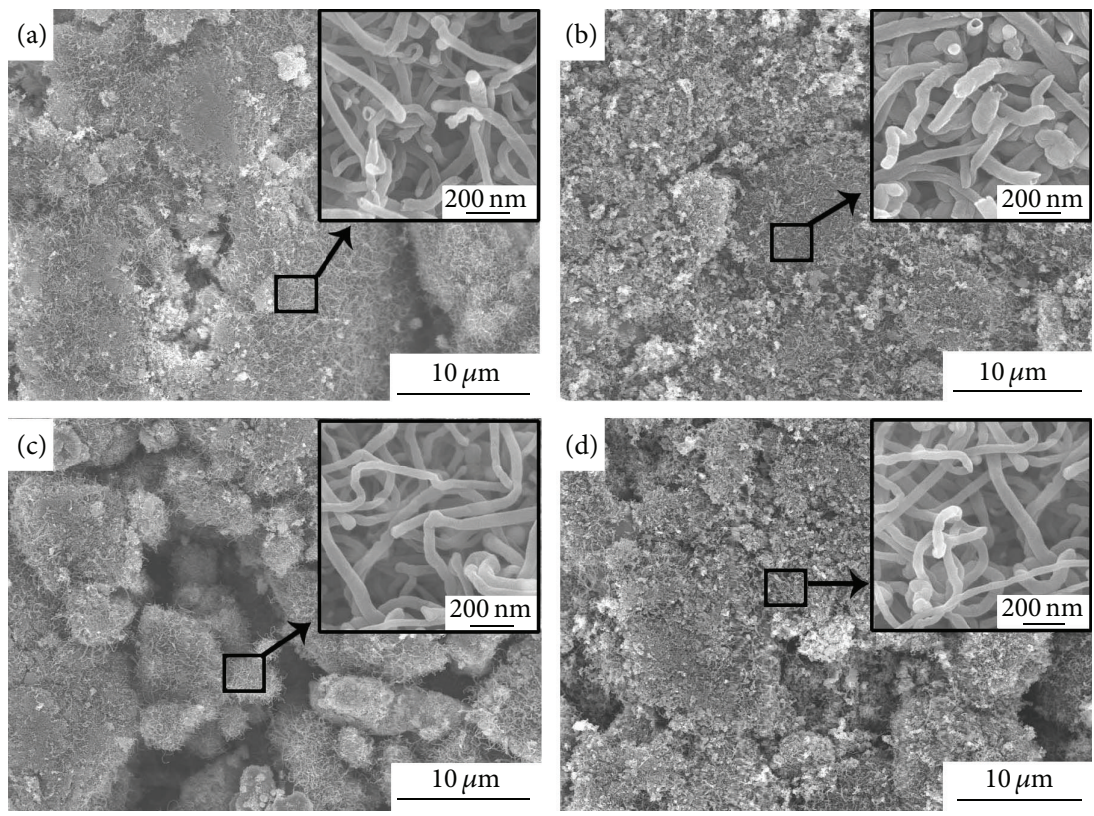

Figure 2: Morphology of synthetic CNTs as a function of reaction temperature. (a), (b), (c), and (d) were $\mathrm{Cu}_{(\mathrm{CNTs})}$ products at $720^{\circ} \mathrm{C}, 770^{\circ} \mathrm{C}$, $820^{\circ} \mathrm{C}$, and $870^{\circ} \mathrm{C}$, respectively.

for nickel phase slightly occurred; this was responsible for this phenomenon that solid solution had formed during catalytic decomposition process as carbon had deposited, adsorbed, and reacted with nickel oxide to form Ni-C solid solution, so crystal lattice changes led to diffraction peak right shifts. The carbon atom structure of tube wall for CNTs was similar to that for graphite lattice plane (002); diffraction peak of graphite (002) lattice plane can be observed at $26.2^{\circ}$ from XRD patterns for all samples. While other lattice planes such as (100), (101), and (102) presented a position overlap with diffraction peaks position of metal $\mathrm{Cu}$ and $\mathrm{Ni}$, it was difficult to separate diffraction peaks of CNTs from that of $\mathrm{Cu}$ and $\mathrm{Ni}$.

The morphology observations were executed for CNTs grown at different reaction temperatures in Figure 2; (a), (b), (c), and (d) represented CNTs products at $720^{\circ} \mathrm{C}, 770^{\circ} \mathrm{C}$, $820^{\circ} \mathrm{C}$, and $870^{\circ} \mathrm{C}$, respectively. For all samples synthesized under different reaction temperatures, CNTs products were distributed uniformly on the surface of copper powders. The agglomeration was not obvious. The average diameter was $34 \mathrm{~nm}, 39 \mathrm{~nm}, 47 \mathrm{~nm}$, and $52 \mathrm{~nm}$ for the CNTs grown at $720^{\circ} \mathrm{C}, 770^{\circ} \mathrm{C}, 820^{\circ} \mathrm{C}$, and $870^{\circ} \mathrm{C}$, respectively. The diameter dimension of newly synthesized CNTs were within the scope of $30 \sim 60 \mathrm{~nm}$. CNTs with smooth outer wall were shown in Figures 2(a), 2(b), and 2(c). With reaction temperature increasing, CNTs diameter of as-product CNTs became bigger. However, outer wall of CNTs became slightly rough when reaction temperature reached $870^{\circ} \mathrm{C}$. From SEM result for end region morphology of CNTs with high magnification, spherical catalyst particles were detected on the end region of CNTs. Ni/MgO particles at CNTs tips implied the tip-growth mechanism. The results were similar to Chen's reports [10]. They found that highly aligned MWCNTs were synthesized in vertical channels of AAO template in the ECR-CVD system using a gas mixture of $\mathrm{CH}_{4}$ and $\mathrm{H}_{2}$ after electroplating of Co catalyst into pore bottom. Co particles embedded at their tips were considered to imply the "tip-growth" mechanism. Compared with the aforementioned finding, in this work, growth behavior of CNTs on the surface of copper powders by CVD method was considered to follow as "tip-growth" mechanism. In our investigation, CNTs on copper powder were anisotropic, which was considered to be in favour of improvement for heat conducting property of the $\mathrm{CNTs} / \mathrm{Cu}$ composite in the subsequent research.

The multiwall carbon nanotubes were successfully obtained at $700^{\circ} \mathrm{C}$ utilizing NiMCM-41 (or Ni/MCM-41) as a catalytic template by means of the pyrolysis of ethanol as reported by Zhao and his collaborators [11]. The abovementioned research showed that $\mathrm{Ni}$ was chosen as a typical catalyst to fabricate MWCNTs with uniform diameter and high quality. In this investigation, $\mathrm{Ni} / \mathrm{MgO}$ was applied as a catalyst to synthetize CNTs on the surface of copper powders. The synthesis yield of CNTs for $8 \mathrm{wt} . \% \mathrm{Ni} / \mathrm{MgO}$ powders was examined by varying deposit reaction temperature between $720^{\circ} \mathrm{C}$ and $870^{\circ} \mathrm{C}$ in Figure 3. The minimum carbon yield can be obtained as deposit reaction temperature was $720^{\circ} \mathrm{C}$. As reaction temperature increased, carbon yield had a rising trend. The highest yield of carbon product reached 278\% as reaction temperature was $820^{\circ} \mathrm{C}$. At higher temperature $\left(870^{\circ} \mathrm{C}\right)$, decrease in carbon deposit was attributed to agglomeration and deactivation of metal particles. The carbon yield decreased as reaction temperature further increased. So decomposition of carbon source was diminished at low temperatures. When reaction temperature increased, agglomeration of metal particles became obvious, so metal particle size increased, which resulted in bigger diameter of CNTs. The deactivation effect of $\mathrm{Ni} / \mathrm{MgO}$ catalyst enhanced as 


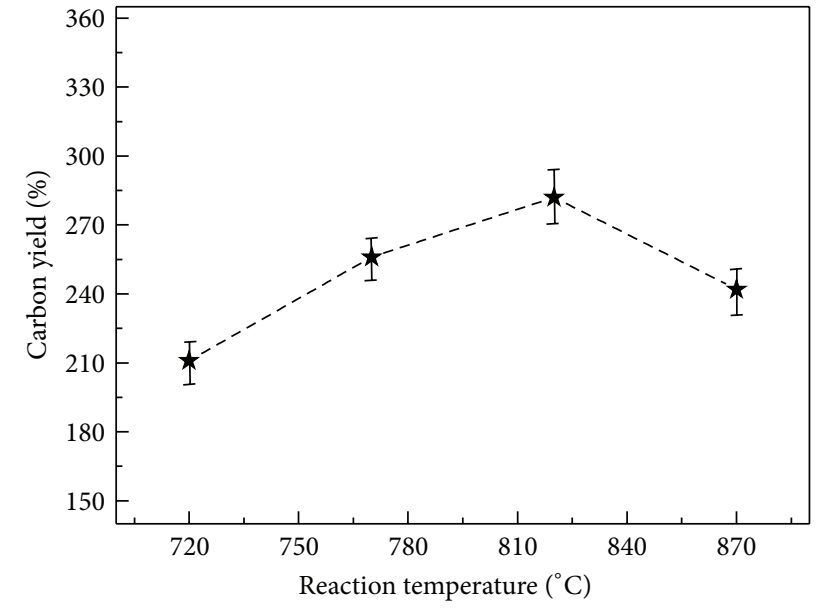

FIGURE 3: The carbon yield produced from $8 \mathrm{wt} . \% \mathrm{Ni} / \mathrm{Cu}$ catalyst as a function of reaction temperature.

the temperature rose, so it tended to be inactive towards more formation of amorphous carbon. When reaction temperature was too high, decomposition rate of methane was higher than diffusion rate of carbon in catalyst; the excess carbon was adsorbed onto catalyst surface. It resulted in deactivation of Ni catalyst, so it was hazardous for growth of CNTs. Thus catalyst had shown highest catalytic activity at $820^{\circ} \mathrm{C}$ only due to higher activity in decomposition of methane and more catalytic conversion of a gaseous precursor to improve more carbon yields. Hence, reaction temperature played an important role to obtain high yield of CNTs. In view of high axial-direction thermal conductivity of carbon nanotubes, anisotropic CNTs on copper powder were introduced into copper matrix material, which was considered to be of benefit for fabricating copper matrix composites with high heat conductivity. So it had a far-reaching significance to obtain high yield of CNTs. In addition, we had fabricated $\mathrm{CNTs} / \mathrm{Cu}$ composites with the above-mentioned $\mathrm{CNTS}_{(\mathrm{Cu})}$ by cold-press molding and pressureless sintering method. Preliminary study suggested that even if addition of CNTs to copper matrix composites was $2 \mathrm{wt} . \%$, Vickers hardness was increased by $270 \%$ and thermal conductivity increased by about $208 \%$ by comparison with pure copper materials under the same experiment condition. We will publish related researched results in subsequent articles.

Raman spectra of synthesized CNTs under different reaction temperatures were shown in Figure 4. For all samples, a broad peak was detected within region of $1587 \sim 1598 \mathrm{~cm}^{-1}$, which was attributed to the graphitic structure with a certain degree of crystallinity as a result of in-plane vibrations of $\mathrm{sp}^{2}$ bonded carbon atoms in the graphitic layers and called tangential mode or G-band for CNTs. It was worth noting that the peak intensity of G-band for CNTs became stronger as the deposition reaction temperature increased. The high degree of symmetry and order structure of carbon materials produced graphitic band (G-band) within the region of $1550 \sim 1600 \mathrm{~cm}^{-1}$ which was generally applied to identify

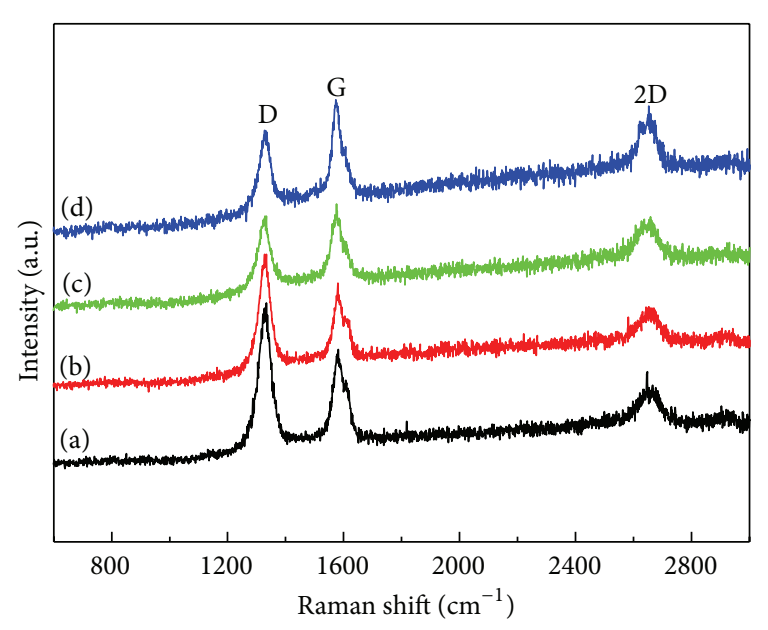

FIGURE 4: Raman spectra of $\mathrm{CNTs}_{(\mathrm{Cu})}$ under different reaction temperatures. (a), (b), (c), and (d) represented reaction temperature of $720^{\circ} \mathrm{C}, 770^{\circ} \mathrm{C}, 820^{\circ} \mathrm{C}$, and $870^{\circ} \mathrm{C}$.

CNTs [12]. From results of intensity of G-band peak of synthesized CNTs $(\mathrm{Cu})$ under different reaction temperatures, we can draw a conclusion that crystallization of well-ordered CNTs would improve gradually as reaction temperature enhanced. The research from Zhang et al. [13] showed that iron oxide particles were attached onto the sidewalls of MWCNTs by thermal decomposition of cyclopentadienyl iron(II) dicarbonyl dimer. The red shift of G-mode from $1579 \mathrm{~cm}^{-1}$ to $1571 \mathrm{~cm}^{-1}$ in the Raman profile of decorated MWCNTs was indicative of the attachment of nanoparticles. From the results of the above-mentioned report, we found that iron oxide nanoparticles led to red shift of G-mode in the Raman profile. In our investigation, we did not detect this phenomenon. D-band peak of $\mathrm{CNTs}_{(\mathrm{Cu})}$ under different reaction temperature was illustrated in Figure 4. Broad Dband peak was within the scope of 1385 1399 $\mathrm{cm}^{-1}$, which exhibited defects from lattice distortion. For CNTs, D-band peak was detected at $1250 \sim 1450 \mathrm{~cm}^{-1}$ in Raman spectrum and it had a high sensitivity to the disordered structures in carbon materials. In addition, the intensity ratio of D-band to G-band $\left(I_{\mathrm{D}} / I_{\mathrm{G}}\right)$ was the important character of extensive defects in the CNTs structures. From Raman spectra results of $\mathrm{CNTs}_{(\mathrm{Cu})}$, intensity ratio of D-band to G-band $\left(I_{\mathrm{D}} / I_{\mathrm{G}}\right)$ increased as deposition reaction temperature increased. It implied that order degree of graphitic structure in the synthesized CNTs improved; the results were in agreement with previous reports $[14,15]$.

\section{Conclusion}

In this investigation, carbon nanotubes (CNTs) were introduced onto the surface of copper micrometer particles by thermal CVD technique. The nickel nanoparticles were formed on the surface of copper powders by means of codeposition method, which was a benefit for uniform growth of CNTs. The growth behaviors of CNTs were in Section 3. The results proved that CNTs were distributed 
uniformly on the surface of copper powders for all samples synthesized at different reaction temperatures. CNTs diameter was within the scope of $30 \mathrm{~nm} \sim 60 \mathrm{~nm}$. Growth process of CNTs by CVD method was considered to be "tip-growth" mechanism. From Raman spectra results of CNTs, order degree of graphitic structure in synthesized CNTs improved as deposition reaction temperature increased. The red shift of G-mode in the Raman profile for CNTs had not been detected even if $\mathrm{Ni} / \mathrm{MgO}$ catalyst particles were detected on the tip of CNTs.

\section{Competing Interests}

The authors declare that they have no competing interests.

\section{Acknowledgments}

The authors are grateful for the support by National Science Foundation of China (no. 51271088) and Science and Technology Innovation Team of Jiamusi University (no. Cxtd2013-03).

\section{References}

[1] B. Kruszka, A. P. Terzyk, M. Wiśniewski, P. A. Gauden, and M. Szybowicz, "Synthesis of carbon nanotubes and nanotube forests on copper catalyst," Materials Research Express, vol. 1, no. 3, 2014.

[2] S. Berber, Y.-K. Kwon, and D. Tománek, "Unusually high thermal conductivity of carbon nanotubes," Physical Review Letters, vol. 84, no. 20, pp. 4613-4616, 2000.

[3] Y. Xie, L. Lu, Y. Tang, and Q. Chen, "Grafting carbon nanotubes onto copper fibers using a one-step chemical vapor deposition process," Materials Letters, vol. 153, pp. 96-98, 2015.

[4] S. L. Katar, A. González-Berríos, J. De Jesus, B. Weiner, and G. Morell, "Direct deposition of bamboo-like carbon nanotubes on copper substrates by sulfur-assisted HFCVD," Journal of Nanomaterials, vol. 2008, no. 1, Article ID 515890, 2008.

[5] Y. Homma, H. Liu, D. Takagi, and Y. Kobayashi, "Single-walled carbon nanotube growth with non-iron-group 'catalysts' by chemical vapor deposition,” Nano Research, vol. 2, no. 10, pp. 793-799, 2009.

[6] Y. Champion and Y. Bréchet, "Effect of grain size reduction and geometrical confinement in fine grained copper: potential applications as a material for reversible electrical contacts," Advanced Engineering Materials, vol. 12, no. 8, pp. 798-802, 2010.

[7] M. Lungu, V. Tsakiris, E. Enescu et al., "Development of W-Cu$\mathrm{Ni}$ electrical contact materials with enhanced mechanical properties by spark plasma sintering process," Acta Physica Polonica A, vol. 125, no. 2, pp. 327-330, 2014.

[8] W. M. Daoush, B. K. Lim, C. B. Mo, D. H. Nam, and S. H. Hong, "Electrical and mechanical properties of carbon nanotube reinforced copper nanocomposites fabricated by electroless deposition process," Materials Science and Engineering A, vol. 513-514, pp. 247-253, 2009.

[9] Z. W. Xue, L. D. Wang, P. T. Zhao, S. C. Xu, J. L. Qi, and W. D. Fei, "Microstructures and tensile behavior of carbon nanotubes reinforced $\mathrm{Cu}$ matrix composites with molecular-level dispersion," Materials and Design, vol. 34, pp. 298-301, 2012.
[10] P.-L. Chen, J.-K. Chang, C.-T. Kuo, and F.-M. Pan, "Anodic aluminum oxide template assisted growth of vertically aligned carbon nanotube arrays by ECR-CVD," Diamond and Related Materials, vol. 13, no. 11-12, pp. 1949-1953, 2004.

[11] Q. Zhao, T. Jiang, C. Li, and H. Yin, "Synthesis of multi-wall carbon nanotubes by Ni-substituted (loading) MCM-41 mesoporous molecular sieve catalyzed pyrolysis of ethanol," Journal of Industrial and Engineering Chemistry, vol. 17, no. 2, pp. 218222, 2011.

[12] C. Guiderdoni, C. Estournès, A. Peigney, A. Weibel, V. Turq, and C. Laurent, "The preparation of double-walled carbon nanotube/Cu composites by spark plasma sintering, and their hardness and friction properties," Carbon, vol. 49, no. 13, pp. 45354543, 2011.

[13] W. Zhang, V. Stolojan, S. R. P. Silva, and C. W. Wu, "Raman, EELS and XPS studies of maghemite decorated multi-walled carbon nanotubes," Spectrochimica Acta Part A: Molecular and Biomolecular Spectroscopy, vol. 121, no. 5, pp. 715-718, 2014.

[14] R. Sule, P. A. Olubambi, I. Sigalas, J. K. O. Asante, and J. C. Garrett, "Effect of SPS consolidation parameters on submicron $\mathrm{Cu}$ and $\mathrm{Cu}-\mathrm{CNT}$ composites for thermal management," Powder Technology, vol. 258, pp. 198-205, 2014.

[15] K. T. Kim, S. I. Cha, S. H. Hong, and S. H. Hong, "Microstructures and tensile behavior of carbon nanotube reinforced $\mathrm{Cu}$ matrix nano composites," Materials Science and Engineering A, vol. 430, no. 1-2, pp. 27-33, 2006. 

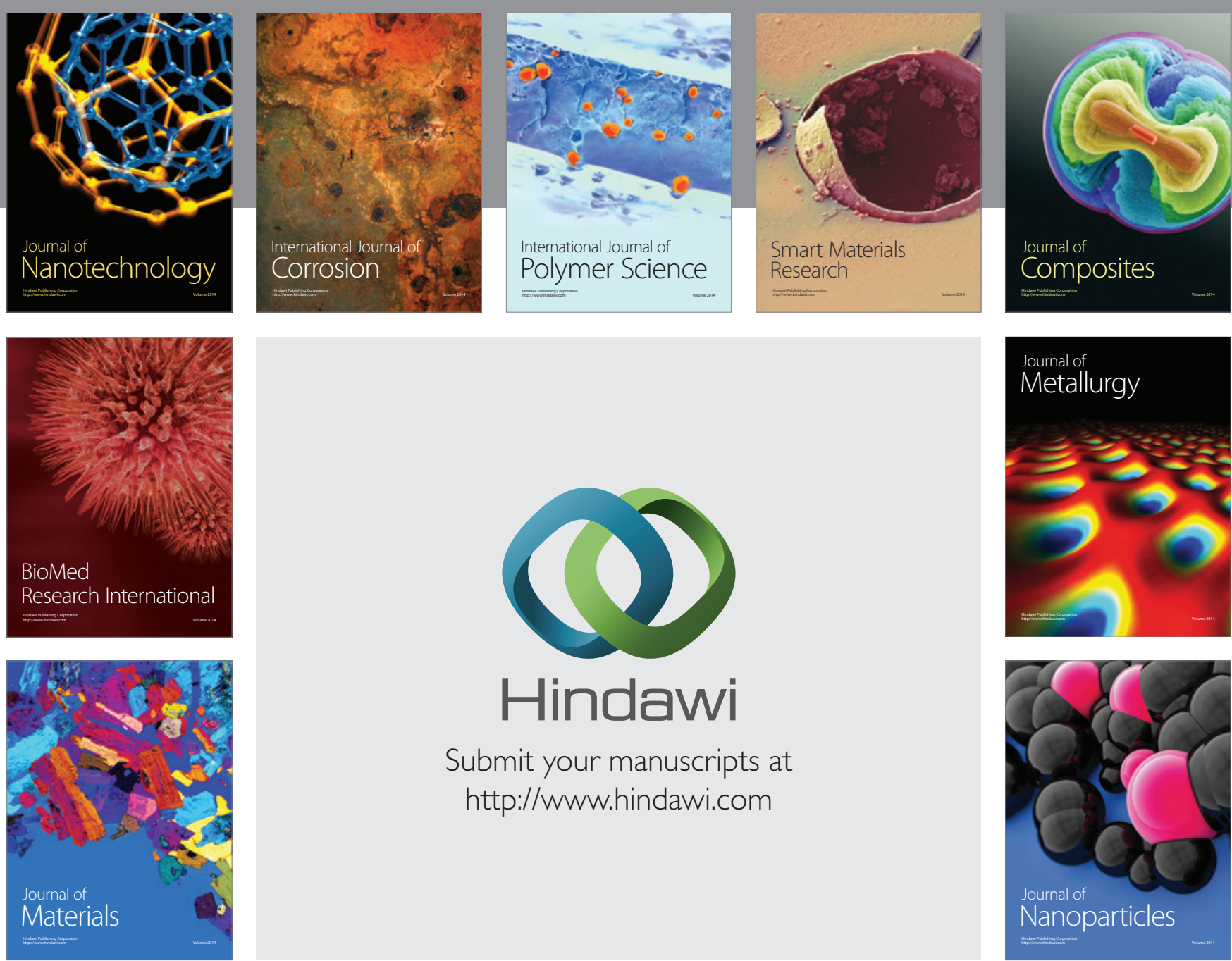

\section{Hindawi}

Submit your manuscripts at

http://www.hindawi.com

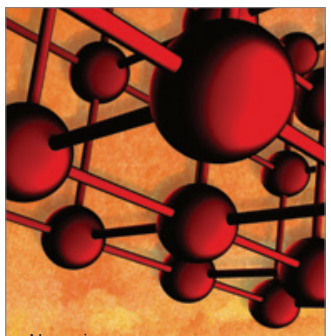

Materials Science and Engineering
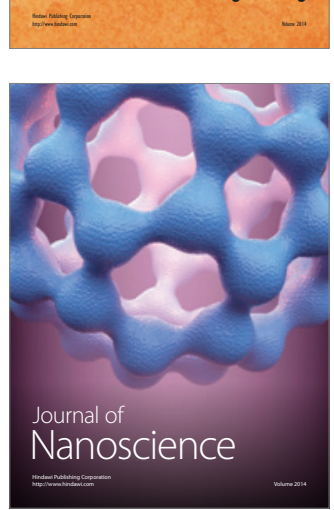
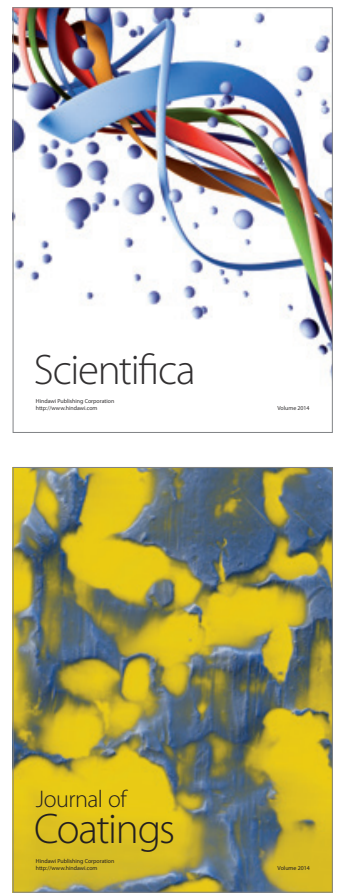
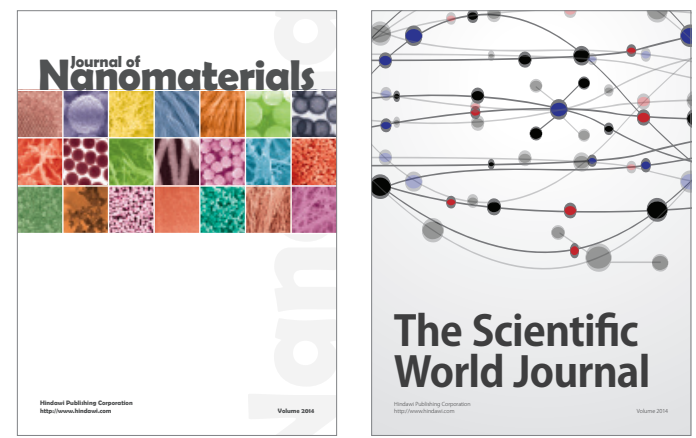

The Scientific World Journal
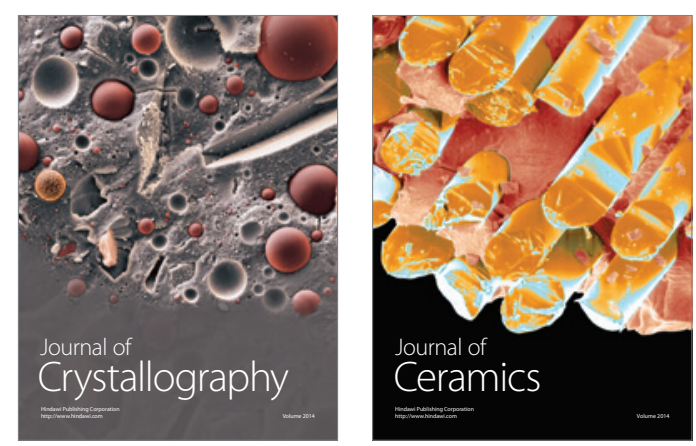
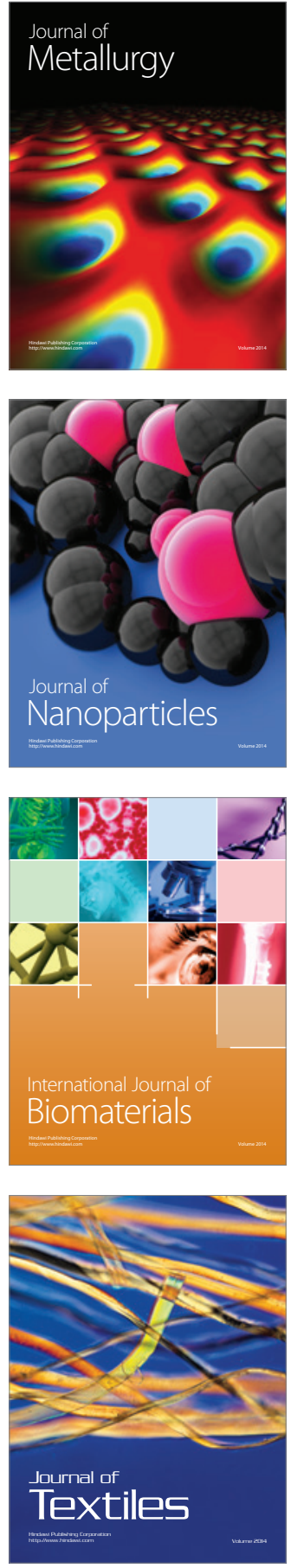